Proc. of the XI Int. Conf. - Ion Implantation and other Applications of Ions and Electrons, Kazimierz Dolny 2016

\title{
Composition of Surface Layers Prepared by Ion Beam Assisted Deposition of Catalytic Metals from Pulsed Arc-Discharge Plasma onto Carbon Paper Substrates
}

\author{
V.V. POPlavsky ${ }^{a, *}$, V.G. LUhin ${ }^{a}$ And T.N. KOLTUnOWiCZ ${ }^{b}$ \\ ${ }^{a}$ Belarusian State University of Technology, 13a, Sverdlov Str., 220006 Minsk, Belarus \\ ${ }^{b}$ Lublin University of Technology, Nadbystrzycka 38a, 20-618 Lublin, Poland
}

\begin{abstract}
The layers were prepared by ion beam assisted deposition of iridium and platinum onto AVCarb ${ }^{\circledR}$ Carbon Fiber Paper P50 electrocatalyst supports for the production of diffusion layers of the membrane-electrode assemblies of low temperature fuel cells with polymer electrolyte membrane. Formation of the layers in the ion beam assisted deposition mode, by means of the deposition of metal and mixing of precipitating layer with the substrate by the accelerated $(U=10 \mathrm{kV})$ ions of the same metal, was performed. In this process neutral fraction of metal vapour and ionized plasma of vacuum pulsed electric arc discharge were used. The investigations of morphology and composition of layers were carried out by the scanning electron microscopy, energy dispersive X-ray microanalysis, wave dispersive X-ray fluorescence analysis, and the Rutherford backscattering spectrometry methods. It was established that the obtained catalytic layers contain atoms of the deposited metals and substrate material as well as impurity oxygen atoms. The surfaces contain also metal inclusions of several micrometer size which arise from the precipitation of deposited metal droplets from the arc discharge of an ion source. The content of iridium and platinum atoms in the layers is $\approx 2 \times 10^{16} \mathrm{~cm}^{-2}$; the concentration of the deposited metals equals about several atomic percent.
\end{abstract}

DOI: 10.12693/APhysPolA.132.295

PACS/topics: 68.37.Hk, 81.15.Jj, 81.05.U-, 82.80.Yc

\section{Introduction}

Ion-beam treatment of substances provides an opportunity of implanting controlled amounts of a dopant into their surface layers under the non-equilibrium conditions. Ion-beam modification of the materials whose operating abilities, particularly physicochemical (catalytic and corrosive) properties, are mainly controlled by the surface composition is of particular interest [1-11].

The aim of this work is to study the composition and morphology of surface layers produced by the ion beam assisted deposition of catalytic metals (iridium and platinum) onto carbon paper electrocatalyst supports.

\section{Experimental details and results}

As catalyst support there is applied the selected special carbon material AVCarb ${ }^{\circledR}$ Carbon Fiber Paper (AVCarbCFP) (Ballard Material Products Inc.) [12] for the production of diffusion layers of the membrane-electrode assemblies of low temperature fuel cells with a polymer electrolyte membrane. Surface pretreatment of samples of the carbon paper supports was not required.

The investigated layers were prepared by the ion beam assisted deposition (IBAD) of platinum, iridium and iridium, platinum alternately onto carbon catalyst supports. The deposition method is characterized by the

*corresponding author; e-mail: vasily.poplav@tut.by use of deposited-metal ions as assisting ones. Metal deposition and mixing between the precipitable layer and surface of the substrate by accelerated ions of the same metal were performed from a neutral vapor fraction and plasma of vacuum arc discharge of a pulsed electric arc ion source. Ion accelerating voltage is $10 \mathrm{kV}$; vacuum $10^{-2} \mathrm{~Pa}$.

The elemental composition and morphology of the obtained layers were studied by scanning electron microscopy (SEM) together with the electron probe energy dispersive X-ray microanalysis (EDX), wave dispersive $\mathrm{X}$-ray fluorescence analysis (WD-XRF), and the Rutherford backscattering spectrometry (RBS).

Electron microscopic study of the surface layers in conjunction with electron energy dispersive microanalysis was conducted using the combined scanning electron microscope with spectrometer: JSM-5610LV + EDX JED2201 (JEOL), and LEO 1455 VP + AZtec Energy Advanced X-Max80 (Oxford Instruments). Also the distribution of elements on the surface of the layers was analyzed. The energy of electrons scanning the surface of the materials was $20 \mathrm{keV}$.

WD-XRF analysis of the catalytic layers was conducted using the PANalytical Axios spectrometer. The $\mathrm{Rh} K$ line is used to excite $\mathrm{X}$-ray fluorescence of atoms embedded in the tested samples. The crystal LiF (200) serves as a monochromator-analyzer.

The study of the layers by the Rutherford backscattering spectrometry was carried out using the AN-2500 accelerator complex (High Voltage Engineering Europe). The spectra were obtained at the initial ${ }^{4} \mathrm{He}$ ions energy 
1.0 MeV. The RBS spectra were taken at the normal incidence of the ${ }^{4} \mathrm{He}$ ion beam on the surface of the sample and the scattering angle $\theta=170^{\circ}$. The energy resolution of the spectrometer with a surface-barrier silicon detector was $18 \mathrm{keV}$. Standard processing of the RBS spectra was performed.

The electron microscopic studies indicate that the surface morphology of the carbon substrate remained substantially unchanged after layers formation (Figs. 1, 2). At the same time on the studied surface there are precipitated particles of metals whose size is several $\mu \mathrm{m}$ (Figs. 2, 3a), due to the deposition of metal droplets from the arc-discharge ion source. Droplet formation is often undesirable because it leads to heterogeneity of the composition and properties of the plasma formed by depositing metal coating. To eliminate dripping onto the surface there is used a special plasma flow transportation system whose operation is based on the rejection of the charged fraction in the magnetic field [13]. However, separation of ionized and neutral fractions does not allow using the IBAD mode.
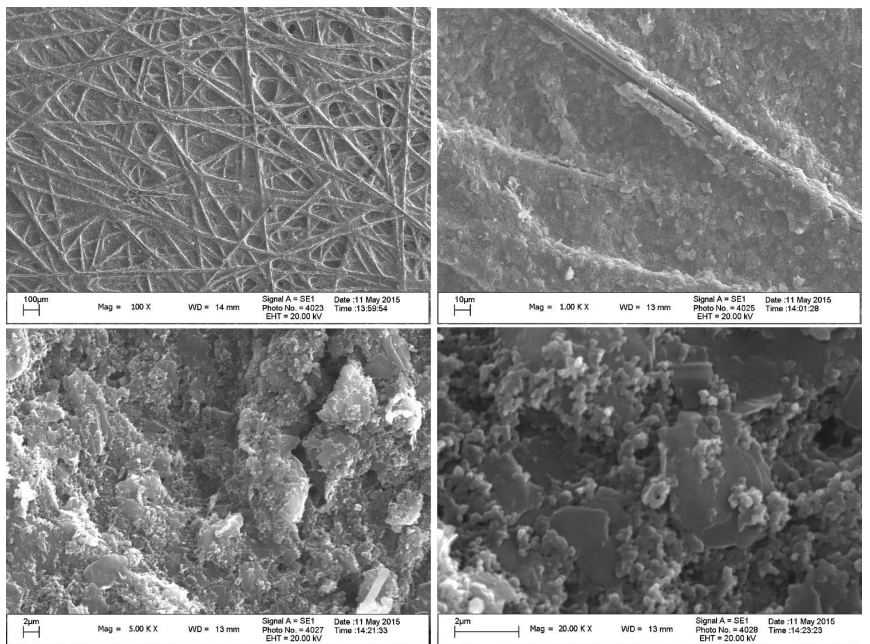

Fig. 1. SEM images of the surface layer prepared by platinum IBAD onto AVCarb ${ }^{\circledR}$ Carbon Fiber Paper P50 catalyst support taken at different magnifications.

Figure 3 shows the SEM image of the surface layer prepared on the AVCarb ${ }^{\circledR}$ Carbon Fiber Paper P50 catalyst support by IBAD of iridium and platinum (a), and the EDX spectra of platinum (b) and iridium (c) droplet particles. Using the SEM-EDX method, resolving of the spectral lines of platinum and iridium causes some problems. Investigations of such particles make it possible to determine the presence of both deposited metals. According to the electron probe energy dispersive microanalysis the content of deposited platinum and iridium in the catalytic layers is about several weight percent. Moreover, the iridium content in the investigated layer is smaller than that of platinum. The element concentrations obtained from the EDX measurements are calculated from the area $1.5 \times 1.0 \mathrm{~mm}^{2}$. Deposited atoms

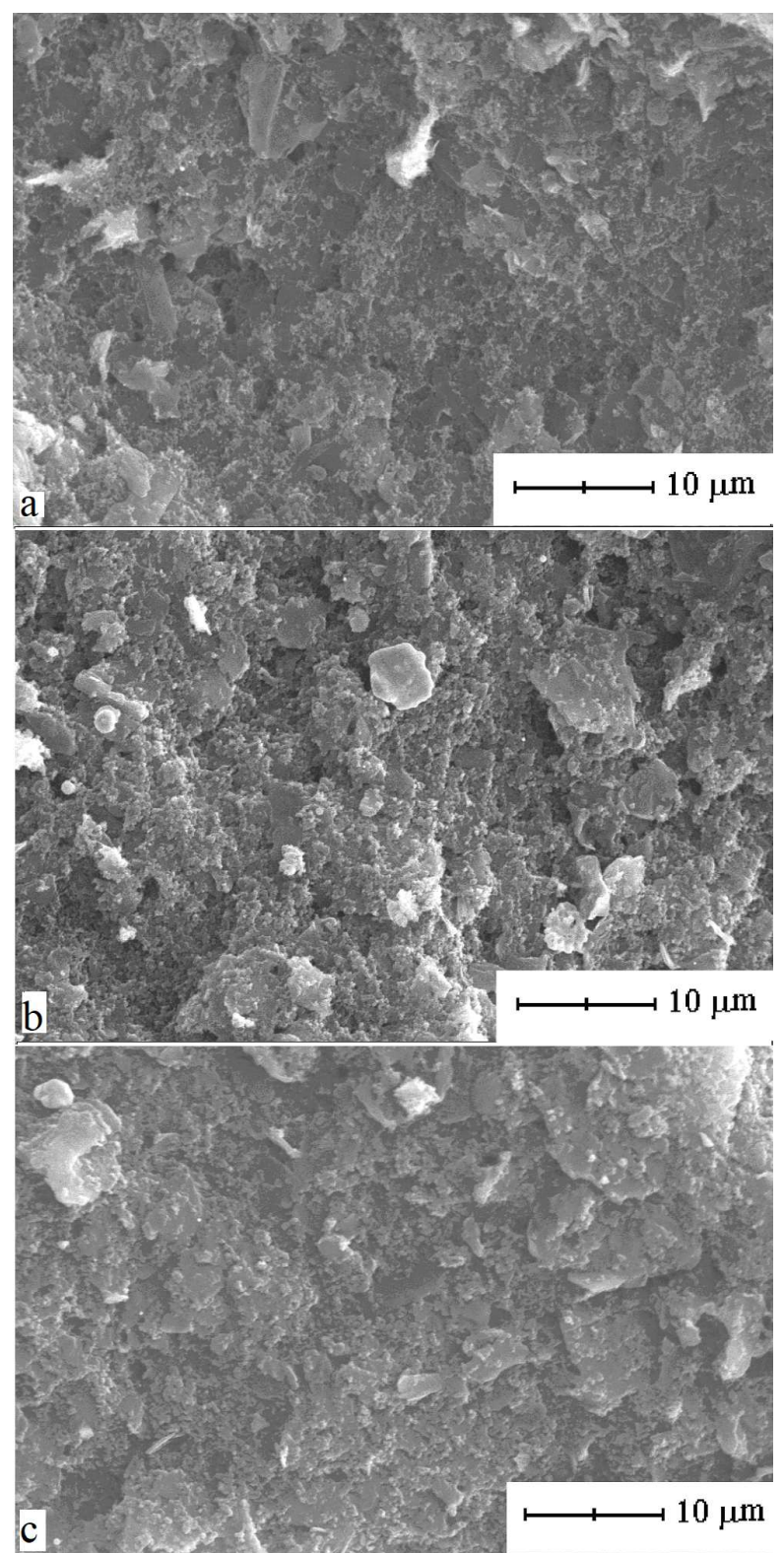

Fig. 2. SEM images of the surface layers prepared on AVCarb ${ }^{\circledR}$ Carbon Fiber Paper P50 catalyst support by IBAD of iridium (a), platinum (b), iridium and platinum alternately $(\mathrm{c})$.

of elements are unevenly distributed on the surface due to the non-uniform morphology of the carbon substrate.

Presence of the deposited metals in the prepared layers is detected by their study with the use of WD-XRF analysis. Figure 4 shows the X-ray fluorescence spectra plots of platinum (Fig. 4a,b) and iridium (Fig. 4c) atoms included in the layers formed on the basis of the AVCarb ${ }^{\circledR}$ Carbon Fiber Paper P50 catalyst supports by IBAD of platinum and iridium, respectively. The obtained spectra are composed of the $L$ - and $M$-series spectral lines of the characteristic X-ray of platinum atoms, and $M$-series of iridium atoms radiation. 

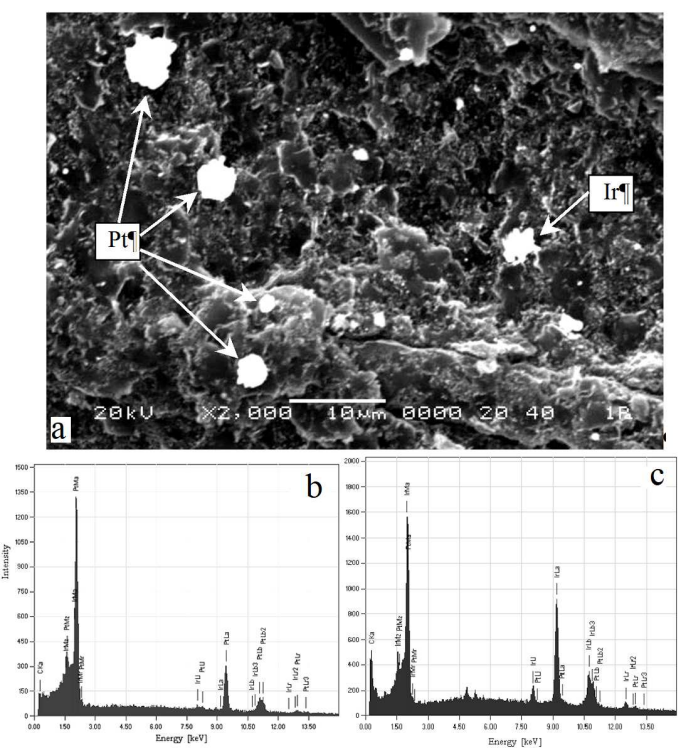

Fig. 3. SEM image of the surface layer prepared on AVCarb ${ }^{\circledR}$ Carbon Fiber Paper P50 catalyst support by IBAD of iridium and platinum (a), and the EDX spectra of platinum (b) and iridium (c) particles.

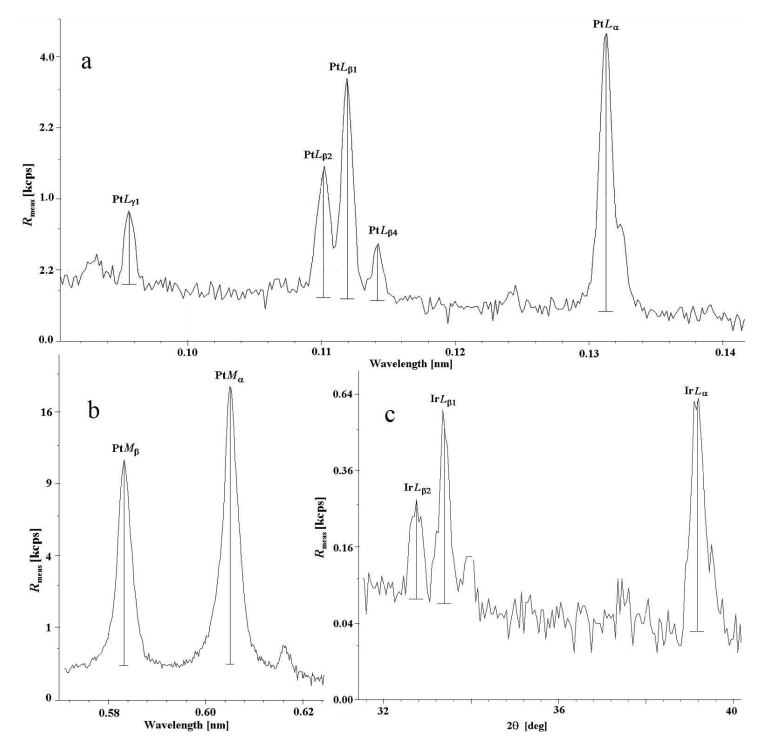

Fig. 4. Parts of WD-XRF spectra of the platinum (a, b) atoms composed of the layer prepared by platinum IBAD, and iridium (c) atoms in the layer prepared by iridium IBAD onto AVCarb ${ }^{\circledR}$ Carbon Fiber Paper P50 catalyst supports.

RBS spectrometry data also confirm the composition of the prepared layers. Figure 5 shows the spectra of ${ }^{4} \mathrm{He}$ ions scattered from the AVCarb ${ }^{\circledR}$ Carbon Fiber Paper P50 catalyst supports with the layers prepared by IBAD of iridium (Ir/AVCarbCFP), platinum (Pt/AVCarbCFP), iridium and platinum alternately (Ir, $\mathrm{Pt} /$ AVCarbCFP). The composition of the studied cata-

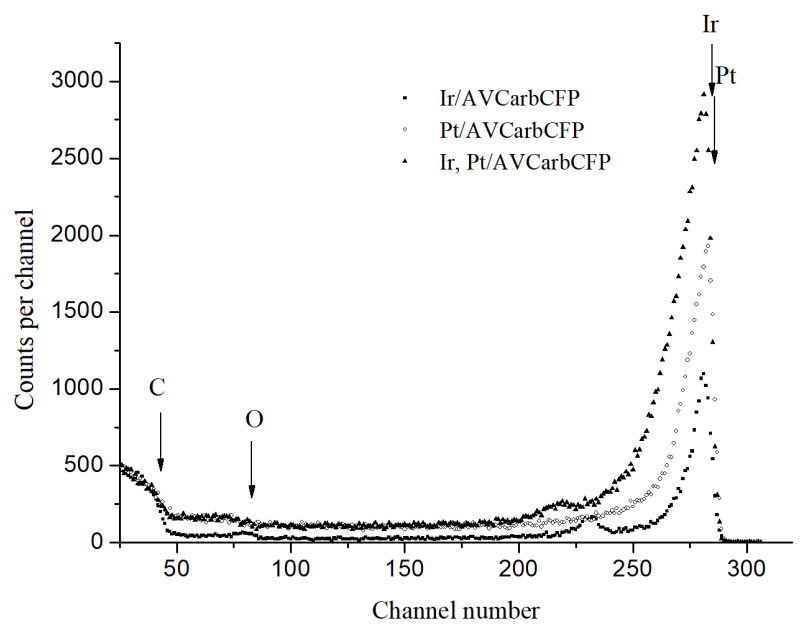

Fig. 5. RBS spectra of ${ }^{4} \mathrm{He}$ ions scattered from the AVCarb ${ }^{\circledR}$ Carbon Fiber Paper P50 catalyst supports with layers prepared by IBAD of iridium (Ir/AVCarbCFP), platinum (Pt/AVCarbCFP), iridium and platinum alternately (Ir, Pt/AVCarbCFP).

lytic layers includes atoms of deposited metals, carbon catalyst supports, and oxygen impurities. The presence of oxygen is due to the deposition of residual atmosphere of the working vacuum chamber, and sorption processes. According to the RBS data the concentration of the deposited metal atoms at the distribution maximum is a few atomic percent, the thickness of the catalytic layer is about $100 \mathrm{~nm}$, the content of iridium and platinum atoms in the layers is in the range $(1.5-3.4) \times 10^{16} \mathrm{~cm}^{-2}$ (Table I).

TABLE I

Content of implanted atoms of elements in the layers prepared by iridium and platinum IBAD onto AVCarb ${ }^{\circledR}$ carbon fiber paper P50 catalyst supports samples (according to RBS data).

\begin{tabular}{c|c|c|c}
\hline \hline \multirow{2}{*}{ Element } & \multicolumn{3}{|c}{ Content $\left[\times 10^{16} \mathrm{~cm}^{-2}\right]$} \\
\cline { 2 - 4 } & Ir/AVCarb & Pt/AVCarb & Ir,Pt/AVCarb \\
\hline Ir & 1.4 & - & 3.4 \\
$\mathrm{Pt}$ & - & 2.2 & 2.9 \\
$\mathrm{O}$ & 1.7 & 2.0 & 3.5
\end{tabular}

When depositing iridium some features appear at the depth distribution of metal atoms. In the high-energy region of the Ir/AVCarbCFP and Ir, Pt/AVCarbCFP RBS spectra there are two peaks caused by the scattering of helium ions on the nuclei of atoms of heavy elements. It can be assumed that the iridium atoms penetrate deep into the carbon substrate. The results of estimation for the Ir/AVCarbCFP spectrum by evaluation processing show that the atomic concentration of iridium at the maximum distribution of atoms near the surface to a depth of $\approx 40 \mathrm{~nm}$ is $4 \%$, then gradually decreases to about $0.1 \%$ at a depth of about $500 \mathrm{~nm}$ 
and at a depth of $\approx 1300 \mathrm{~nm}$ increases to approximately $0.25 \%$. The background signal of the Ir/AVCarbCFP and Ir, Pt/AVCarbCFP spectra in the channels range from 90 to 195 (Fig. 5) is due to scattering of ${ }^{4} \mathrm{He}$ ions with nuclei of the deposited metal atoms in the droplet phase. Furthermore, there is a mixing of components of layers by the accelerated ions of deposited metals.

\section{Conclusion}

Formation of active layers on the carbon fiber paper catalyst support surface takes place by IBAD of catalytic metals, i.e. platinum and iridium from the plasma of vacuum arc discharge ion source in the pulsed mode, in which the metal is introduced into the catalytic layer on the atomic level under processing conditions with the accelerated ions of the deposited metal. This ensures the addition of the substrates under the vacuum conditions of small amounts of dopant and formation of active layer tightly bound to the matrix with low activating metals content that stands out from the traditional multi-step chemical catalyst preparation methods.

Using the EDX, WD-XRF, and RBS experimental methods it was found that the formed catalytic layers include atoms of the deposited metal (Pt, Ir), carbon substrate and oxygen impurities. The layer thickness was about $100 \mathrm{~nm}$, the content of active metals is smaller than $5 \times 10^{16} \mathrm{~cm}^{-2}$; their concentration in the distribution peak located at a depth of less than $40 \mathrm{~nm}$, i.e., a several atomic percent. When iridium is deposited, diffusion of metal atoms reaches the depth of about $1 \mu \mathrm{m}$. According to EDX microanalysis the content of deposited platinum and iridium in the catalytic layers is about several weight percent.

The layers formed by IBAD on the massive smooth metallic [5-7] and carbon [8] substrates have very low (less than $0.05 \mathrm{mg} / \mathrm{cm}^{2}$ ) platinum content and exhibit high electrocatalytic activity in practically important, oxidation processes of organic alcohols, i.e. methanol and ethanol. The use of AVCarb ${ }^{\circledR}$ Carbon Fiber Paper P50 as a catalyst support can provide preparation of electrocatalysts for the membrane electrode assemblies of fuel cells with the polymer electrolyte membrane.

\section{References}

[1] G.K. Wolf, R. Spiegel, K. Zucholl, Nucl. Instrum. Methods Phys. Res. B 19/20, 1030 (1987).

[2] V.V. Poplavskij, Nucl. Instrum. Methods Phys. Res. B 28, 534 (1987).

[3] G.K. Wolf, Nucl. Instrum. Methods Phys. Res. B 46 , 369 (1990).

[4] F.F. Komarov, V.V. Poplavskij, Radiat. Eff. 106, 1 (1988).

[5] V.V. Poplavskii, T.S. Mishchenko, V.G. Matys, J. Surf. Invest. 4, 576 (2010).

[6] V.V. Poplavskii, T.S. Mishchenko, V.G. Matys, Tech. Phys. 55, 296 (2010).

[7] V.V. Poplavskii, T.S. Stel'makh, V.G. Matys, J. Surf. Invest. 6, 748 (2012).

[8] V.V. Poplavskii, A.V. Dorozhko, J. Surf. Invest. 7, 303 (2013).

[9] V.V. Poplavsky, A.V. Dorozhko, V.G. Matys, I.P. Smiaglikov, S.O. Selifanov Izv. vuzov. Phizica 58, 126 (2015) (in Russian).

[10] V.V. Poplavsky, F.F. Komarov, V.G. Luhin, V.V. Pil'ko, J. Partyka, Acta Phys. Pol. A 128, 946 (2015).

[11] V.V. Poplavsky, A.V. Dorozhko, V.G. Matys, J. Surf. Invest. 10, 981 (2016)

[12] AvCarb Datasheets, (accessed: 18.05.2016).

[13] V.A. Osipov, P.P. Sablev, R.I. Stupak, Pribor. Techn. Experiment 6, 173 (1978) (in Russian). 